\title{
Study of Incinerated Silver Used in Indian Traditional Medicine Systems
}

\author{
Subhathirai Subramaniyan Parimalam ${ }^{1}$, Ahmad Sohrabi ${ }^{1}$, Simona Badilescu1, Rama Bhat ${ }^{2}$, Alisa \\ Piekny $^{3}$, Muthukumaran Packirisamy ${ }^{1}$ \\ ${ }^{1}$ Concordia University, Optical-Bio Microsystems Laboratory, Micro-Nano-Bio Integration Center, Department of \\ Mechanical and Industrial Engineering, Montreal, H3G 1M8, Canada. \\ ${ }^{2}$ Concordia University, Department of Mechanical and Industrial Engineering, Montreal, H3G 1M8, Canada. \\ ${ }^{3}$ Concordia University, Department of Biology, Montreal, H4B 1R6, Canada. \\ subhathi@encs.concordia.ca, ahmad.sohrabi@gmail.com, simonabadilescu0@gmail.com, rama.bhat@concordia.ca, \\ alisa.piekny@concordia.ca,mpackir@encs.concordia.ca
}

\begin{abstract}
Incinerated metal particles such as gold, silver, copper and iron are administered as internal medicines in the Indian systems of medicine, Siddha and Ayurveda, respectively. We studied the structure, composition and properties of the Incinerated Silver (IAg) particles (Veli parpam/Rajata bhasma) as well as their spectra and localisation in cancer cells (HeLa, A549 and HCT 116). The average crystallite size, particle size, and hydrodynamic diameter were found to be $54.6 \mathrm{~nm}, 300 \mathrm{~nm}$ to $1.7 \mu \mathrm{m}$, and $530 \mathrm{~nm}-1.1 \mu \mathrm{m}$, respectively. The particles have a negative surface charge with a zeta potential of $-22.87 \pm 1.34 \mathrm{mV}$. The IAg particles are made up of $\mathrm{Ag}, \mathrm{Ca}, \mathrm{Fe}, \mathrm{Hg}$ and other trace elements. Further, their subcellular properties and locations were analysed in cancer cell lines. The preliminary results obtained from the SEM and hyperspectral imaging show the uptake of the IAg particles and aggregates.
\end{abstract}

Keywords: Silver ash, Indian medicine, Siddha medicine, hyperspectral imaging.

(C) Copyright 2020 Authors - This is an Open Access article published under the Creative Commons Attribution License terms (http://creativecommons.org/licenses/by/3.0). Unrestricted use, distribution, and reproduction in any medium are permitted, provided the original work is properly cited.

\section{Introduction}

The Indian systems of medicines, namely Siddha and Ayurveda, use incinerated metal products of gold, silver, copper and iron as oral medicines. The metalbased medicine is the last expedient when herbal medicine-based treatments become ineffective. The incinerated metals have been used for centuries to treat chronic diseases, including cancer and immunological disorders. During oral administration, the incinerated metal is given in a small dosage $(\sim 100 \mathrm{mg}$ over a period of 3-7 days) along with herbal extracts or/and dairy products, depending on the disease condition. More than one disease can be treated using the same metal by simply varying the adjuvants (bio-enhancers) [1]. Metal medicines have a longer shelf-life in comparison to organic plant-based medicines. In addition, they are tasteless, quick to act and can be used in low dosage.

In the era of nanomedicines, it was hypothesised that the rapid therapeutic effect of the incinerated metal medicines is due, in part, to their size and negative surface charge. Some of the particles have a large surface area to volume ratio and, therefore, greater capacity for delivery. Further, the negative charge of the metal nanoparticles, combined with their size may account for their rapid cellular uptake.

Although there were no tools to measure nanomicro scale particles during the medieval period, numerous simple qualitative methods, specific to Siddha and Ayurveda, were employed to validate the metal products [2]. The IAg preparation is a top down process, the bulk material is broken down into fine particles through repeated levigations in plant extracts, followed by numerous incineration cycles as described in the ancient texts.

In this work we studied the IAg particles [3], [4], also called as Veli parpam [5], [6] and Rajata bhasma, [1], [7], in Siddha and Ayurveda, respectively. The IAg particles have been, and still are, used to treat lung diseases (tuberculosis) neurological conditions 
(insomnias, neuralgias, anxiety disorders) [8], infections (gonorrhoea) and skin diseases (leprosy, eczema) among other ailments [6]. The IAg particles are administered orally in a small dosage along with bioenhancers such as butter or herbal mixtures [9].

More than hundred methods are available to prepare the IAg particles, and they can be broadly classified into two categories, one that includes mercury, which results in an amalgam intermediate during the fabrication process, and the others, without mercury [6]. In spite of its toxicity, mercury is believed to be the ideal medium to prepare any metal-based medicine and is extensively used in Siddha metal-based medicines as well as in Ayurveda. In both cases, the bulk metal undergoes numerous physicochemical processes that are believed to remove the potential toxicity of the final product [10], [11].

Each pharmaceutical company uses a different method of fabrication. The one used to prepare IAg for our study is briefly described below. The materials used are, silver foils, mercury, egg shells and Pergularia Daemiar leaf extract. The Ag foils are grinded with mercury, the amalgam is then levigated in the Daemic leaf juice [12]. The end product is made into small cakes, dried and incinerated at around $700^{\circ} \mathrm{C}$ [11] and the grinding and incineration cycles are repeated two more times. The egg shells are added to the IAg and levigated again with the Daemic leaf juice and incinerated repeatedly until a fine powder is obtained.

Some of the limitations while administering metal particles are tissue retention and renal clearance [9]. Numerous studies were carried out to determine the particle size, chemical composition and nano-bio cellular interactions [13]-[15]. However, their pharmacokinetics and cellular interactions are not fully understood. The main drawback to determining the biological effects of the incinerated particles is their structural complexity and batch to batch variation in size and chemical composition [4].

Attempts to standardize the fabrication of IAg particles have been made by Siddha [4] and Ayurveda scholars respectively [7], [11], [15]. In the last decade, various reports on the physicochemical (particle size, elemental composition, etc.) [14]-[16] and biological properties, such as antibacterial activity [14], antiinflammatory activity [17], analgesic activity [18], sedative-hypnotic activity [8] and hypolipidimic activity [19] [14] of IAg have been reported. Further, the effect of IAg on brain diseases [18], [20], [21] and the cellular uptake of IAg in the presences of various bio-enhancers was also studied [9]. The latter work demonstrated their potential disruption of endothelial tight junctions, which could have implications for the blood brain barrier. They also showed that the IAg particles caused topological changes in two different endothelial cells, CaCo-2, and HT-29. The cells treated with IAg were found to have a well-defined boundaries with fibre-like connection between the cells, whereas the untreated cells were found to be an indistinguishable mass [9].

Recently, our group compared the cellular uptake of Incinerated gold nanoparticles (IAu) with synthesized gold nanoparticles [22]. The intracellular plasmonic spectrum of the IAu was captured, demonstrating their localisation and sub-cellular interactions. While IAu particles were primarily cytosolic and randomly distributed, some were observed in the nuclei. In addition, they required actin-based mechanisms for uptake, which was the first time this had been shown for a metal-based Indian medicine [22].

In this work, we describe the structure, size and elemental composition of IAg particles as well as their location and properties in three cancer cell lines; HeLa, A549 and HCT 116 cells. Hyperspectral imaging and plasmonic properties of IAg particles in human cells was measured for the first time.

\section{Materials and methods}

\section{1. Veli parpam-IAg}

The IAg was purchased from The Indian Medical Practitioners Co-operative Pharmacy \& Stores LTD. (IMCOPS), Chennai, India, batch number: 2016.

\section{2. Physical and chemical properties}

The particle size of the IAg was determined using Scanning Electron Microscopy (SEM) (Hitachi S 3400N). The IAg was suspended in $\mathrm{DDH}_{2} \mathrm{O}$, applied on a cover glass, dried and coated with gold before imaging. The hydrodynamic diameter and the zeta potential of the IAg in $\mathrm{DDH}_{2} \mathrm{O}$ were determined through Dynamic light Scattering (DLS) (Zetasizer Nano S90).

The powder XRD pattern of the IAg was measured with a diffractometer using $\mathrm{CU}-\mathrm{K} \alpha, \lambda=1.5418$ radiation and the elemental composition of the IAg was determined by ICP-MS (Inductively-Coupled Plasma Mass Spectroscopy) with a 7700x Agilent instrument. In order to perform the ICP-MS analysis, IAg was digested in aqua regia $\left(3 \mathrm{HCl}: 1 \mathrm{HNO}_{3}\right)$ at $110^{\circ} \mathrm{C}$.

\section{3. Cell culture}


A549 (lung cancer), HCT 116 (colorectal cancer) and HeLa (cervical cancer) cells were maintained in F12K, McCoy's and DMEM (Wisent) media, respectively. All media were supplemented with $10 \%$ fetal bovine serum (FBS; Thermo Scientific), $2 \mathrm{mM}$ L-glutamine (Wisent), $100 \mathrm{U}$ penicillin (Wisent), and $0.1 \mathrm{mg} / \mathrm{mL}$ streptomycin (Wisent). The cells were incubated at $37^{\circ} \mathrm{C}$ in a humidified chamber with $5 \% \mathrm{CO}_{2}$. They were grown on coverslips placed in a 6 -well dish in $2 \mathrm{~mL}$ of the respective culture media. After the cells reached $40 \%$ confluency, $200 \mu \mathrm{L}$ of IAg suspended in $\mathrm{DDH}_{2} \mathrm{O}$ was added to the media. After 24 hrs of incubation, the culture medium was removed and the cells were washed with PBS and prepared for fixing.

\section{4. Cell fixing and imaging}

The cells were fixed for imaging using trichloro acetic acid (TCA) 10\% w/v in cold water. The cells were incubated in TCA for $14 \mathrm{~min}$ at $4^{\circ} \mathrm{C}$ and washed 3 times with PBST (PBS with $0.3 \%$ Triton X-100) and kept at $4{ }^{\circ} \mathrm{C}$ until staining. Before staining, cells were treated with $5 \%$ normal donkey serum (NDS) in PBST for $12 \mathrm{~min}$ to block non-specific binding sites. Then, the fixed cells were stained for tubulin using 1:400 mouse DM1A, antibodies. After washing, cells were incubated with anti-mouse Alexa 488 secondary antibodies. 4',6Diamidino-2'-phenylindole dihydrochloride (DAPI; Sigma-Aldrich) was used to stain the DNA. Finally, after washing with PBST and $0.1 \mathrm{M}$ Tris $\mathrm{pH}$ 9, mounting media was added to each coverslip, which were mounted on microscope slides and sealed [22]. Cells were imaged for epifluorescence using a Leica DMI600 with a Hamamatsu OrcaR2 CCD, and Volocity acquisition software. Cells that were not incubated with antibodies were used for hyperspectral imaging with the CytoViva Hyperspectral Microscope.

For SEM measurements, the cells were fixed with TCA as described above, washed and gradually dehydrated in $50 \%, 60 \%, 70 \%, 80 \%, 90 \%$ and $100 \%$ ethanol, and stored at $4{ }^{\circ} \mathrm{C}$. The coverslips were coated with gold before SEM imaging.

\section{Results and discussion}

\section{1. Physical and chemical analysis}

The size of the particle is an important feature that determines cytotoxicity and clearance [23]. The nanoparticles are believed to agglomerate and form large aggregates in a broad size range from nano- to micro- meters. The agglomeration is possibly due to the repeated incineration processes. In support of this, the IAg particles measured using SEM varied from $530 \mathrm{~nm}$ to $1.1 \mu \mathrm{m}$ in size (Figure 1). The hydrodynamic diameter of the particles using DLS was largely in agreement with these values, in the range of $300 \mathrm{~nm}$ to $1.7 \mu \mathrm{m}$ (Figure 2). The crystallite size calculated using Scherrer's equation was $\sim 54.6 \mathrm{~nm}$. A similar agglomeration was also observed in IAu and other incinerated metal-medicines. (a)

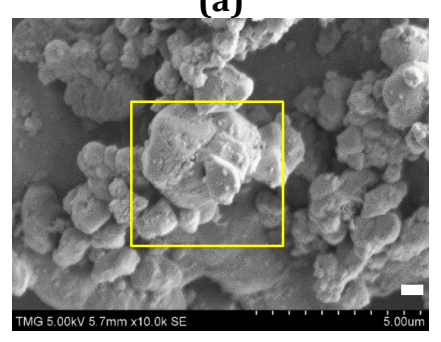

(b)

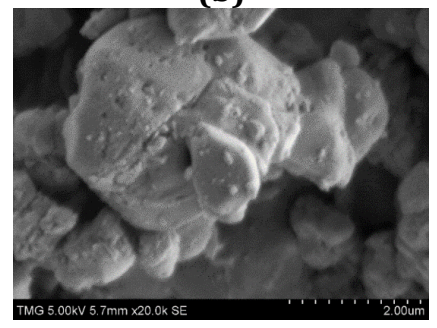

Figure 1. The size of the IAg particles was measured using SEM and was found to be in the range of, $300 \mathrm{~nm}$ to $1-5 \mu \mathrm{m}$.

(a) Shows the IAg particles, irregularly shaped, heterogeneous in size, with smooth edges. Due to the repeated incineration cycles, a great amount of nano IAg particles are believed to agglomerate and form larger micro scale particles (scale bar $5 \mu \mathrm{m}$ ) and (b) is a zoomed in image of the selected region in image (a) (scale bar $2 \mu \mathrm{m}$ ).

The zeta potential of the IAg dispersed in $\mathrm{DDH}_{2} \mathrm{O}$ was measured and found to be $-22.87 \pm 1.34 \mathrm{mV}$. The surface charge is an important parameter that plays a major role in the agglomeration behaviour of the particles [24] and further determines its circulation time [25], protein corona formation [26], cell adsorption, and intracellular fate [27]. Theoretically, there is a preferential adsorption of positively charged particles by the negatively charged cell membrane. However, in general, positively charged particles are more toxic than the neutral and negatively charged ones [28].

The XRD pattern showed the presence of Ag and its oxides. The incineration of pure silver at temperatures above $195^{\circ} \mathrm{C}$ results in silver oxide $\left(\mathrm{Ag}_{2} \mathrm{O}\right)$. However in this case, the intermediate formation of $\mathrm{AgHg}$ (silver amalgam) and the presence of calcium carbonate $\left(\mathrm{CaCO}_{3}\right)$, a suppressor of $\mathrm{Hg}$ oxidation [29], is speculated to have caused the formation of crystalized silver particles [30] (Figure 3). Indeed, the XRD peaks show that the sample is a mixture of Ag, silver oxide and traces of $\mathrm{CaCO}_{3}$. The high intensity of some of the peaks suggests the presence of the atoms in that particular (hlk) plane. 
From the ICP-MS analysis, the IAg was found to contain calcium, iron, silver and mercury. The EDS analysis confirmed the presence of sodium, magnesium, aluminium, silicon, chlorine and potassium.

Metal-based medicines have been shown to contain mixtures of metals. The main metal (silver, in this case) is present in the highest concentration, while the concentration of the other metals is much lower. Most of them originate from the containers used for incineration, the granite mortar and pestle and/or are contaminants from the plant extracts.

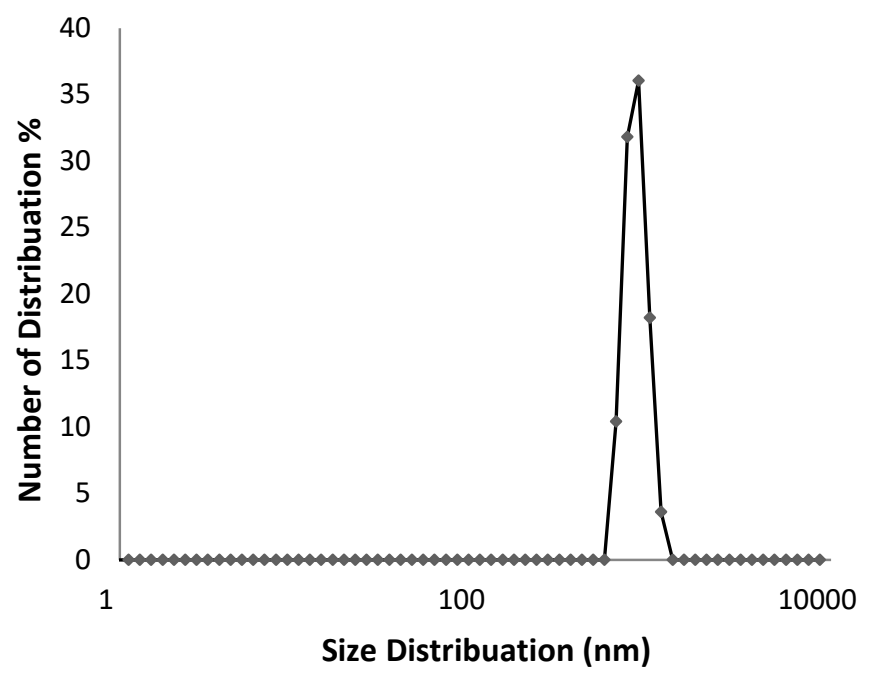

Figure 2. The hydrodynamic diameter of the IAg particles suspended in $\mathrm{DDH}_{2} \mathrm{O}$ was found to be around $1 \mu \mathrm{m}$.

\section{2. Cell studies}

To determine the properties of IAg particles in cells, they were added to HeLa cells for 24 hours, which were then washed, fixed and dehydrated for SEM imaging. The SEM image shows an aggregate of IAg particles inside a cell [Figure 4 (a) and (b)].

To determine if IAg particles are taken up by other cancer cell types and visualize their localization, IAg particles were added to HCT 116 and A549 cells for 24 hours, then fixed and stained for tubulin and DNA. Epifluorescence images show large aggregates of the IAg particles inside both cell types (Figure 5). While the aggregates appear to be more randomly distributed in HCT 116 cells [Figure 5 (b)], they are peri-nuclear in A549 cells [Figure 5 (d)].

To assess the intracellular interactions and properties of IAg particles, hyperspectral imaging was performed. Hyperspectral microscopy in combination with a dark-field reflectance system is an advanced non- invasive and label-free analytical tool to locate and identify nanoparticles in complex biological systems such as human cells. The light scattering properties of plasmonic nanoparticles are combined with spectrophotometry. The system has a powerful resolving capability and is useful for assessing the cellular internalization of nanoparticles.

The hyperspectral image of the IAg particles alone [Figure 6 (i)] were measured and compared with IAg particles in A549 cells [Figure 6 (ii)] and in HCT 116 cells [Figure 6 (iii)]. The larger aggregates are characterized by the longer spectral wavelength of the scattered light in comparison with smaller aggregates [Figure 6 (i)]. In A549 and HCT 116 cells, the particles had a tendency to agglomerate as demonstrated by peaks at their longer wavelengths. Since the gold and silver plasmon bands red-shifts as the size of the particles increases, the larger spectral shift measured for IAg particles in A549 cells $(210 \mathrm{~nm})$ compared to HCT 116 cells $(180 \mathrm{~nm})$ suggests a higher degree of aggregation.

The cellular uptake and location of any metalbased nanoparticle depends on the properties of the particle and the cell type. The location of aggregates by hyperspectral imaging were similar to those measured by epifluorescence microscopy. As was observed in the majority of A549 cells, the IAg particles were largely peri-nuclear suggesting that they entered via phagocytosis or endocytosis and were sequestered in the endomembrane system. However, in HCT 116 cells, the IAg particles were more randomly distributed and could have entered cells through different mechanisms, or entered cells similar to A549 cells, but escaped the system to be more randomly distributed.

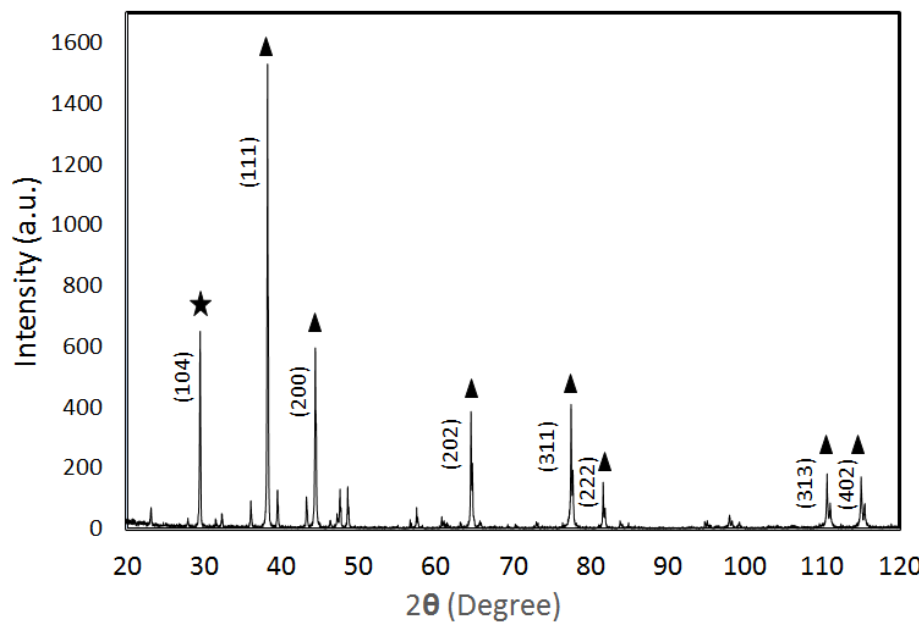

Figure 3. The XRD pattern of IAg. The average crystallite size calculated using Scherrer's equation is $54.6 \mathrm{~nm}$. The star and 
the triangle symbols indicate the calcium and silver peaks respectively.

(a)

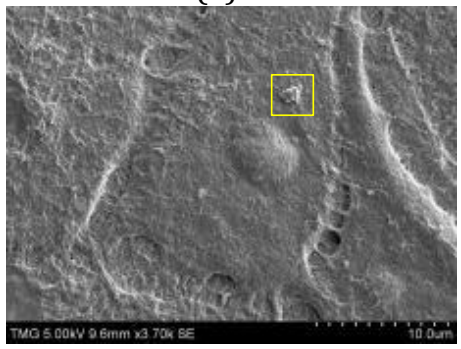

Figure 4. (a) The SEM image of HeLa cells incubated with IAg particles for $24 \mathrm{hrs}$ (scale bar is $10 \mu \mathrm{m}$ ), and (b) the zoomed in image of the selected area (scale bar is $2 \mu \mathrm{m}$ ). (a)

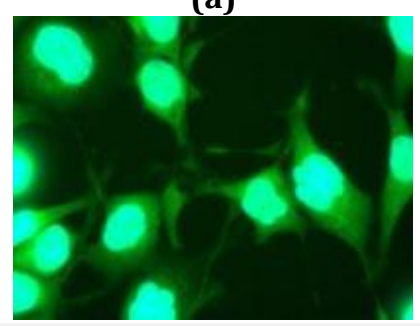

(c)

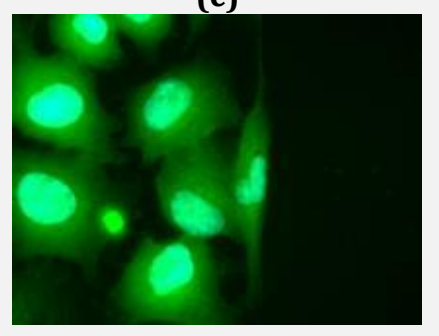

(b)

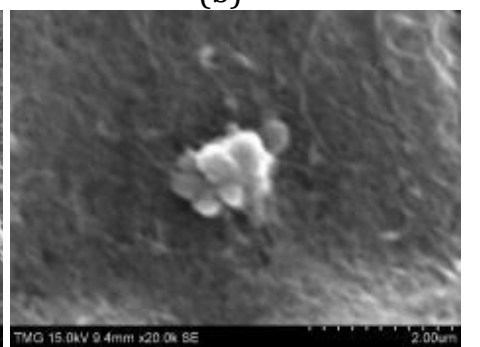

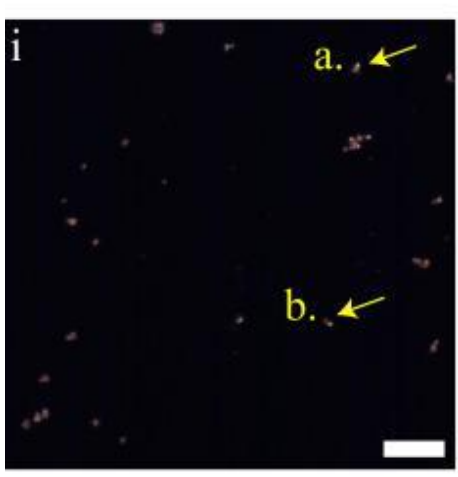

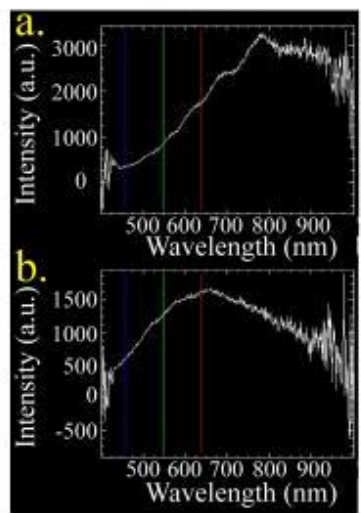

ii
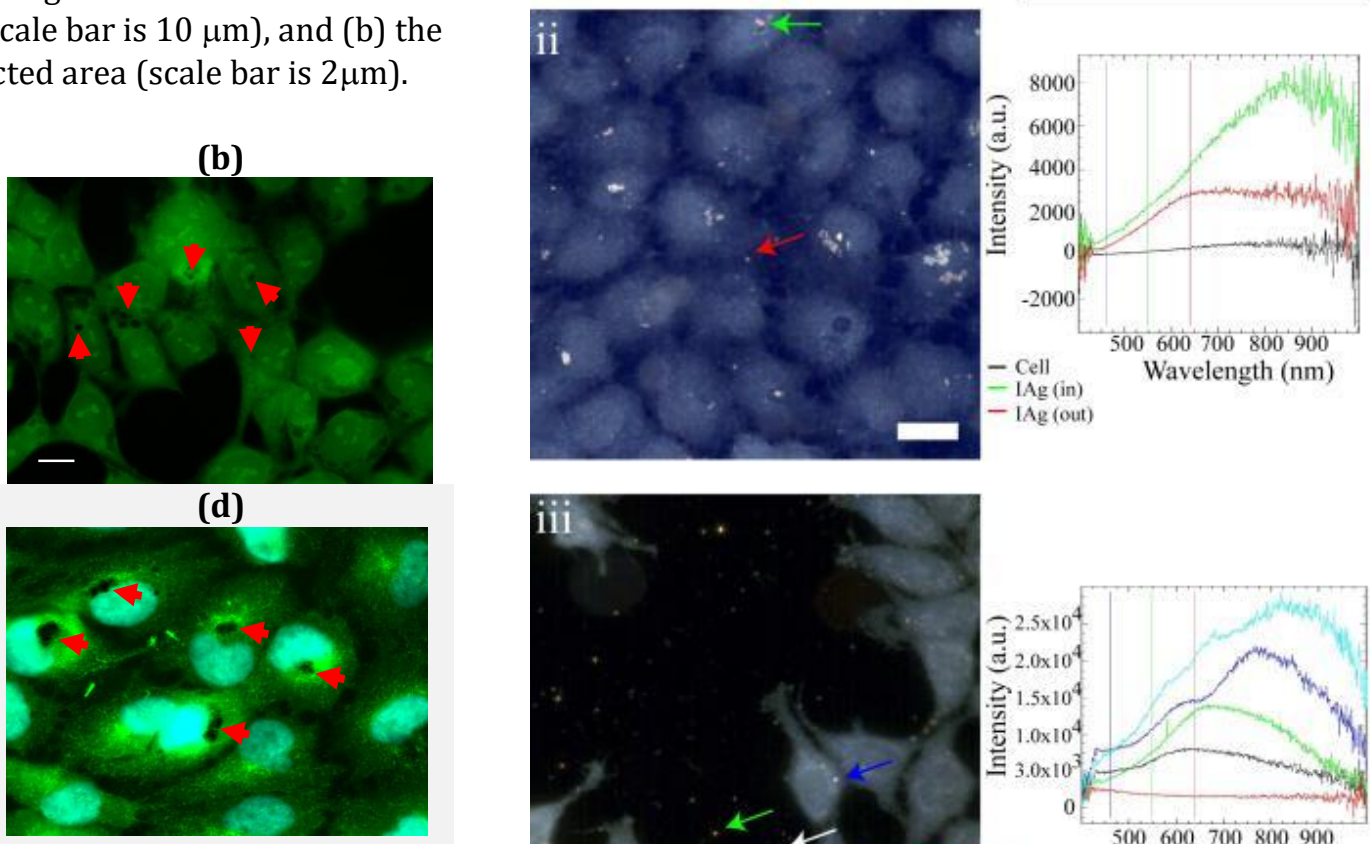

Figure 5. The fluorescence microscopy images of HCT 116 cells (a) control and (b) incubated with IAg for $24 \mathrm{hrs}$, and of A549 cells (c) control and (d) incubated with IAg for 24 hours stained for tubulin(green) and DAPI (blue; scale bar is 20 $\mu \mathrm{m})$. (d)

(b)

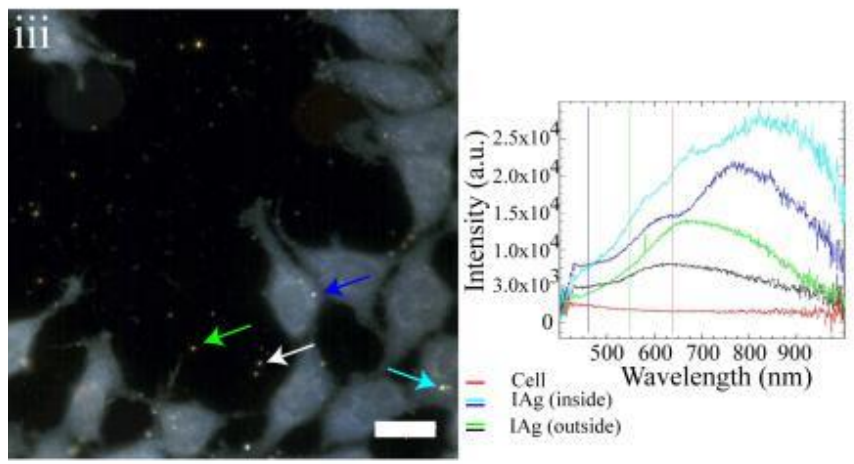

Figure 6. The hyperspectral images of IAg particles alone (i), in A549 cells (ii) and in HCT 116 cells (iii); (scale bar is 20 $\mu \mathrm{m})$.

\section{Conclusion}

In this study, we investigated the size, elemental composition and properties of incinerated silver particles in several cancer cell lines. It has to be noted that the elemental composition may vary from batch to batch and even between individual InDia particles. For this reason, the accuracy of both SEM-EDS and ICP-MS elemental composition results is affected and they should be only seen as average values.

Nanoparticles were found to be aggregated into micron-sized particles, possibly due to their processing using high temperatures. Both SEM and hyperspectral 
images show the presence of large particles and aggregates inside cells. However, the degree of aggregation seemed to vary depending on the cell type suggesting a difference in how the particles are taken up, or how they interact with the intracellular environment.

\section{References}

[1] R. Chaturvedi, S. C. Bhargava, N. Sonkar, and C. B. Jha, "Rajata in Ayurvedic therapeutics," Biomedical and Pharmacology Journal, vol. 2, no. 2, pp. 407-416, 2009.

[2] B. Rohit Ajith Gokarn, "Pharmaceutical standardization of Rajata Bhasma (Incinerated Silver) by two different methods," Annals of Ayurvedic Medicine, vol. 2, no.1-2, pp. 7-15, 2013.

[3] J. W. Alexander, "History of the medical use of silver," Surgical Infections, 10(3):289-92, 2009.

[4] A. Sudha, V. S. Murty, and T. S. Chandra, "Standardization of metal-based herbal medicines," American Journal of Infectious Diseases, vol. 5, no. 3, pp. 193-199, 2009.

[5] M. Pitchiah kumar, J. Jeyavenkatesh, G. Senthilvel, Fundamentals of Siddha Internal Medicine, 2018th ed. Madurai: Shanlax Publications, 2018.

[6] Thiyagarajan R., Gunapadam, 4th ed. Department of Indian Medicine and Homeopathy. Chennai, India, pp. 214, 2004.

[7] R. A. Gokarn, B. Patgiri, and S. G. Hiremath, "Pharmaceutical standardization of rajatabhasma (incinerated silver) by two different methods," Annals of Ayurvedic Medicine, vol. 2, no. 1-2, pp. 715, 2013.

[8] D. Inder and P. Kumar, "Sedative-hypnotic effect of ash of silver in mice: A reverse pharmacological study," Journal of Traditional and Complementary Medicine, vol. 4, no. 4, pp. 268-271, 2014.

[9] S. Mukkavalli, V. Chalivendra, and B. R. Singh, "Physico-chemical analysis of herbally prepared silver nanoparticles and its potential as a drug bioenhancer," vol. 2, pp.19-27, OpenNano, 2017.

[10] H. Kobayashi, "Pharmacokinetics and clearance properties of nano-sized particles and molecules as multi-modality imaging agents: Considerations and caveats," in Technical Proceedings of the 2011 NSTI Nanotechnology Conference and Expo, NSTINanotech 2011, vol. 3, pp. 125-128, 2011.

[11] R. Chaturvedi and C. Jha, "Standard manufacturing procedure of Rajata Bhasma," $A Y U$ (An International Quarterly Journal of Research in
Ayurveda), vol. 32, no. 4, pp. 566-571, 2011.

[12] Formulary of Siddha Medicines, Fourth. Chennai, India: IMPCOPS, 1993.

[13] S. Pal, "The Ayurvedic Bhasma: The Ancient Science of Nanomedicine," Recent Patents on Nanomedicine, vol. 5, no. 1, pp. 12-18, 2015.

[14] R. Sharma, A. Bhatt, and M. Thakur, "Physicochemical characterization and antibacterial activity of Rajata Bhasma and silver nanoparticle," AYU (An International Quarterly Journal of Research in Ayurveda), vol. 37, no. 1, pp. 71-75, 2016.

[15] R. A. Gokarn, S. Kallianpur, K. Hebbar, and K. Madhusudhana, "Characterization of Rajata Bhasma (traditional calcined silver preparation)," International Journal of Green Pharmacy, vol. 11, no. 3, pp. 143-148, 2017.

[16] K. Pardeshi, V. Kadibagil, and B. Ganti, "Therapeutic potential of rajata (silver) bhasma: a review," International Journal of Research in Ayurveda and Pharmacy, vol. 2, no. 2, pp. 55-63, 2017.

[17] S. B. Prasad, Yashwant, and V. Aeri, "In vitro antiinflammatory activity of Raupya (Silver) Bhasma," Journal of Chemical and Pharmaceutical Research, vol. 5, no. 9, pp. 194-197, 2013.

[18] A. T. Khanna, R. Sivaraman, and S. B. Vohora, "Analgesic activity of silver preparations used in India systems of medicine," Indian Journal of Pharmacology, vol. 29, no. 6, pp. 393-398, 1997.

[19] D. C. Sharma, R. Budania, M. Shah, P. Jain, and B. L. Gaur, "Hypolipidemic activity of silver preparations in chicks, Gallus serregineus," Indian Journal of Experimental Biology, vol. 42, no. 5. pp. 504-507, 2004.

[20] P. Devi and C. P. Kashyap, "A clinical evaluation of Rajata Bhasma and Shankhpushpi syrup as medhya," Journal of Ayurveda and Integrative Medicine, vol. 5, no.2, pp. 49-53, 2019.

[21] D. Ekka, S. Dubey, and D. S. Dhruw, "Effect of Rajat Bhasma with Smritisagar Rasa in Parkinson," Journal of Ayurveda and Integrative Medicine, vol. 2, no. 4. pp. 146-150, 2017.

[22] D. Beaudet, S. Badilescu, K. Kuruvinashetti, A. S. Kashani, D. Jaunky, S. Ouellette, A. Piekny and M. Packirisamy, "Comparative study on cellular entry of incinerated ancient gold particles (Swarna Bhasma) and chemically synthesized gold particles," Scientific Reports, vol. 7, article no. 10678, 2017. 
[23] A. R. Gliga, S. Skoglund, I. Odnevall Wallinder, B. Fadeel, and H. L. Karlsson, "Size-dependent cytotoxicity of silver nanoparticles in human lung cells: The role of cellular uptake, agglomeration and Ag release," Particle and Fibre Toxicology, vol. 11, no. 11, pp. 1-17, 2014.

[24] P. Bélteky, Rónavári A, Igaz N, Szerencsés B, Tóth IY, Pfeiffer I, Kiricsi M, Kónya Z, "Silver nanoparticles: Aggregation behavior in biorelevant conditions and its impact on biological activity," International Journal of Nanomedicine, vol. 18, no. 14, pp. 667-687, 2019.

[25] J.-W. Yoo, E. Chambers, and S. Mitragotri, "Factors that Control the Circulation Time of Nanoparticles in Blood: Challenges, Solutions and Future Prospects," Current Pharmaceutical Design, vol. 16, no. 21, pp. 2298-2307, 2010.

[26] A. Abdelkhaliq, M. van der Zande, A. Punt, R. Helsdingen, S. Boeren, Jacques J. M. Vervoort, Ivonne M. C. M. Rietjens and H. Bouwmeester "Impact of nanoparticle surface functionalization on the protein corona and cellular adhesion, uptake and transport," Journal of Nanobiotechnology, vol. 16, no. 70, pp. 1-13, 2018.

[27] N. Durán, C. P. Silveira, M. Durán, and D. S. T. Martinez, "Silver nanoparticle protein corona and toxicity: A mini-review," Journal of Nanobiotechnology. vol. 13, no. 55, pp. 1-17, 2015.

[28] S. Skoglund, J. Hedberg, E. Yunda, A. Godymchuk, E. Blomberg, and I. Odnevall Wallinder, "Difficulties and flaws in performing accurate determinations of zeta potentials of metal nanoparticles in complex solutions - Four case studies," vol. 12, no. 7, article no. e0181735 PLoS One, 2017.

[29] W. Zhou, L. Yu, D. Li, and Y. C. Shiau, "Thermodynamic effects of alkaline earth metals on homogenous mercury oxidation during calcium carbonate (CaCO3) and coal combustion," Toxicological \& Environmental Chemistry, vol. 98, no. 3-4, pp. 303-312, 2016.

[30] R. E. DeRight, "The solubility of silver in mercury. II," Journal of Physical Chemistry, vol. 37, no. 4, pp. 405-4016, 1933. 